\title{
Research on Protection and Construction of Ethnic Language Resources in Northeast China
}

\author{
Zhantao $\mathrm{He}^{\mathrm{a}}$, Hongyu $\mathrm{Li}^{\mathrm{b}}$ \\ College of Literature, Bohai University, Jinzhou, 121013, China \\ ahezhantao@126.com, b928564387@qq.com
}

\begin{abstract}
Keywords: Northeast China; ethnic language; resources protection; resources construction; protection strategies; speech corpus
\end{abstract}

\begin{abstract}
To strengthen protection and inheritance of national language, language can effectively mining the cultural characteristics, analysis of national historical origin, rich ethnic culture, to maintain national unity, promote the development of national economy. This paper analyzes the national language situation in northeast China, summarizes the national language protection predicament in northeast China, through using the experience of foreign national language in protecting, put forward the northeast national language resources protection strategies: realize the digital television multi-language subtitles and pored over in national regions, realize the digitization, national language literature publishing bilingual teaching in ethnic areas, extensive research work of national languages, construction of northeast China national language speech corpus. This article research results, solve the national language resources protection in the northeast of the key issues, and for the protection of ethnic language and traditions of other parts of China to provide the reference.
\end{abstract}

\section{Introduction}

Ethnic language, is refers to the people of a nation in the production and life, communicate thoughts and feelings and networking with the use of language, is one of the basic characteristics of national stability. To keep the rich diversity of national culture, protect the ethnic language, which is beneficial to the inheritance and development of human civilization, but also to national unity and social stability. Multilingual coexist means human cultural diversity and cultural inheriting and maintaining ecosystem. Meaning, on the other hand, a language dies, also means that humans lose a kind of culture, loss of a precious historical and cultural heritage and cultural information source of reference in the comparison. National language is the cultural development in national regions and the testimony of history, is China's national cultural treasures, strengthening the protection of the national language and heritage has far-reaching significance. National language contains a rich content, include stories, legends, fables and philosophy, etc., by strengthening the protection of the minority languages and inheritance, to effectively exploit cultural characteristics of language, rich ethnic culture; National language full of historical experience, strengthen the protection of national language and heritage, help historians in depth analysis of national historical origins; National language loss affect national feelings, strengthen the protection of national languages, can effectively maintain national unity and protect ethnic compatriots of the plot and national emotion.

In northeast China, it is a geographical cultural regions and economic regions of China. Four seasons has China's largest plain in northeast China, is rich in resources, cultural prosperity, economic potentiality is abundant, mainly Han Chinese multi-ethnic cultural depth fusion area, occupies an important position in China. In the northeast of the administrative area include Liaoning, Jilin, Heilongjiang, Inner Mongolia autonomous region east and Chengde, Qinhuangdao city in Hebei province. Northeast is the minorities traditional, including Manchu, Korean, Mongolian, Hui, Daur, Xibe, Hezhen, Olunchun, Ewenki, Kirgiz and dozens of ethnic Russians, etc. To protect and develop the diversity of language and culture has become a problem paid attention to by the United Nations and in various countries and various areas. Our country is to protect the non-material cultural heritage and promote human cultural diversity the signatories of the 
international convention, shall walk in the forefront of the protection of language resources science, in the inheritance and development of human language unique contributions to the cultural diversity. Northeast China national language in China occupies an important place in the national language, through this article research, to provide national language protection and inheritance in northeast China policy, and then to other parts of China's national language protection and inheritance to provide the reference.

\section{General situation of Ethnic Languages in Northeast China}

Historians and historical comparative linguistics home, using the Altaic languages, early have their origin in the north of China. Although dozens of ethnic minorities live in northeast China, but not some minority language and words, some minority language without words, only needs to be protected is the Altai language family in six languages:

(1) Manchu. Text in Mongolia on the basis of improved and become a kind of vertical writing pinyin words, northeast Asia produced and developed a kind of language, is mainly used by the Manchu. Language is a form of expression is rich, colorful language. Middle Qing dynasty Manchu reporting, document, teaching, translating and mainly was used in daily life. The Manchu script font and input method has been available now, can realize the computer input and display correctly.

(2) Xibo language and Manchu language is very similar, the individual letter form of Manchu script changes, increase the necessary sections spelling. Close to the one of the Manchu dialect, the middle of the 18th century some Xibo moved from the Northeast to Xinjiang, then gradually developed into an independent language. Xibo westward, from Uygur, the Kazak and absorbed some of the local Chinese dialect borrowing.

(3) Nanai. Spread in China and Russia border Heilongjiang, Songhua River and Ussuri river area, only the language, no text, is Chinese. Because the Hezhen nationality mainly engaged in fishing and hunting production, therefore the name of the fish is rich. From initial the main communication tool in Hezhen, at present into individual age group of the main communication tools used in certain occasions, Nanai communication function has damping, and the degree of attenuation in growing.

(4) Ewenki nationality language. Ewenki mainly distributed in the eastern Inner Mongolia autonomous region, only the language without words. Is divided into three kinds of dialects, general Mongolian of pastoral areas, general Chinese agriculture and the backer area. Words reflect the mode of livestock production in more, means of word formation mainly derived method, followed by synthesis, loanwords from Chinese and Mongolian. The grammatical meaning mainly by word after stem and various additional ingredients, said the subject-predicate structure of verb predicate.

(5) Oroqen language. Olunchun population less, mainly distributed in the Inner Mongolia autonomous region in northwest of Heilongjiang province and eastern, live together with in with other coexistence environment, at present, a lot of young children to use Chinese, with the Mongolian long district of Olunchun, multi-purpose Mongolian. Oroqen language is only a language, no text. Reflect the hunting activities of production and unique way of life and the vocabulary is very rich, this is also the characteristics of the Oroqen language vocabulary.

(6) Jurchen language. Jurchen language is an ancient Jurchen in 10 to 15 century early use of language. Jurchen language used initially Nuzhen, and then this text gradually died. After the Yuan dynasty, blended in a lot of Mongolian loanwords in the Jurchen language. Nuzhen characters of simple structure, borrows the strokes of Chinese characters spelling the Jurchen language, belong to the ideogram, writing from top to bottom, from right to left a newline. Jurchen language is the progenitor of Manchu language that is the inheritance and development of Jurchen language.

\section{Protection Predicament of Ethnic Languages in Northeast China}

The protection of endangered languages is the responsibility of all over the world. However, a weak culture to resist strong under the globalization of culture shock, cannot leave the academic support, more can't depart from the support of governments and protection. So, in recent years, has been 
calling for the United Nations educational, scientific and cultural organization, hope governments make efforts to save the language and cultural heritage, in order to protect the diversity of language.

Worldwide, there are many reasons for the endangered language phenomenon, and there are natural causes, and some natural causes. On the one hand, language contact is the main reasons for language endangered. Strong and weak language, after close contact with necessary language in the use of weaker field narrowed. At the same time, the formation of the endangered language phenomenon with language situation, the structure of the national economy, society and culture, the development of transportation and communications have indirect; Endangered language phenomenon, on the other hand, is also the result of the social progress and development. Because with the acceleration of global economic integration, the growing communication between people, the mass media such as broadcasting, television, telephone and network is increasingly developed, some of the weak language unable to adapt to the demand of the social communication and information transmission losing communication effect, finally replaced by a strong language, it is not for man's subjective will transfer the objective trend of the development of human society. In addition, disease, and war and forced assimilation, as well as the modern social life in the process of language development of convergence trend, will make some cultural weak national language communication space gradually atrophic, eventually dying.

Currently in northeast China appears the trend of national language use are greatly reduced, the plight of national language protection there are three main reasons: one is that national regions to speed up the localization process, mandarin is more and more popular, national language TV media is not developed, only a small amount of national language channel, TV programs, no appeal; Second, speed up the urbanization process, more and more people choose to urban living, especially most of young people to study, work and life, city people use Chinese national language gradually forgotten; Three is, level of education backward ethnic ghettos, ethnic language learning education, managerial condition is poor, the lack of adequate funding and language education resources, lack of science and technology equipment of language learning, engaged in language teaching could not meet the requirements of teachers' professional level, the protection and inheritance of ethnic languages exist a lot of pressure.

\section{Protection Experience of Ethnic Languages in Foreign Regions}

The United Nations educational, scientific and cultural organization problem of endangered languages especially the panel's essay, points out that the vigor and language endangered in 6000 languages in the world, about $96 \%$ less than $3 \%$ of the users of the human population, language means that every language users, on average, only 30000 people. 6000 languages all over the world, there are at least half of the language, the use of the population is shrinking, the 21st century, in most parts of the world, about $90 \%$ of the language may be replaced by a strong language. So the protection and construction of national language resources and great responsibility is imminent. Under the background of modernization and globalization, the protection of ethnic language is a complicated social project, is a worldwide difficult problem. Developed countries started relatively early in the protection of national languages, there are a lot of experience is worth reference, summarized as follows:

(1) Advocate multicultural values. Modern complex social structure, need different culture serves the social development, that created the diversity of culture, is the complicated social background of multi-culture. Multiculturalism emphasizes respect for cultural diversity. Under the multicultural values, national language protection measures taken by the developed countries mainly includes: the members of the national implementation of bilingual education, the government supports the use of national language newspapers and radio and television programs, provide public services use national language.

(2) Establish a perfect legal system. Perfect legal system is the precondition of effective protection of national language. Minority political demands to rise into law, can improve the status of the national language, from the national legislation to eliminate administrative barrier, ensure that the scope of use and effectiveness. Passed, for example, the Frith orchid language protection 
and culture in Dutch, includes the use Frisian education, judicial system, courts, public administration, journalism, cultural activities, such as economic and life issues.

(3) Ensure the education of national language. National language education, is refers to the student to carry on the national language teaching, the purpose is to cultivate students ability to apply the national language tools, to make it better service to the study of the national culture. Part of the national language education of national education, do a good job in national language education is the basis of the inheritance and protection of ethnic culture. Many countries have noticed the importance of national language education to protect national culture, gradually to seek various policies to guarantee the education of national language.

(4) Pay attention to the role of non-governmental organizations. Non-governmental organizations at local, national or international level is established, in order to promote economic development and social progress for the purpose of social organization, providing a variety of services and play a humanitarian role, reflect citizen concern to the government, supervision policies and encourage political participation at the community level. Many countries give full play to the role of non-governmental organizations, to promote the development and prosperity of culture and national language protection.

\section{Protection Strategies of Ethnic Language Resources in Northeast China}

In view of the national language protection predicament in northeast China, draw lessons from foreign regional ethnic language protection experience, combined with the authors' years of national culture and national language protection research, reference related literature, in the northeast national language resources conservation strategies are as follows:

(1) Realize digital TV multi-language subtitles and pored over in ethnic minority areas. Modern civilization to restrict a lot of people in the family circle, TV became part of popular culture, people puts more and more spare time to lock in the television screen, television become the window on the world and the cognitive world. Although the Internet as the fourth media and increasingly popular computer game is decomposition of the people's attention and amateur life, but the TV's dominance will exist for a long time, and to a certain extent, with a large audience around way of thinking and behavior. History in constant progress, with the rapid development of science and technology, television is provided with plenty of information resources for people at the same time, also in a greater impact on human civilization and national quality and impact. Realize the digital television multi-language subtitles and pored over in national regions, people in the entertainment at the same time, the benefit of the influence of the national language, to further promote the spread of ethnic culture and language.

(2) Published literature digitization realizing national language. Digital publishing is to point to the Internet information provider, their creation or others work after choosing, editing, and digital production, posted on the Internet or sent to the client via the Internet, for many people online at the same time, through reading, use, or download the spread of behavior. Establish a national language literature digital storage and network service, is the national language is an important part of digital development. Digital publishing requires not only the national language of literature text content digitization, more important is to adapt to all kinds of digital carrier, realize digital reading terminal. Published in the new media age, ethnic literature digitization, take advantage of when new media platform, instant messenger software, Internet, mobile terminals, Weibo and WeChat, wider public information service, improve efficiency, and promote the national language in use and promotion, for the personnel engaged in national studies provide more accurate and quick access to information.

(3) The bilingual teaching in ethnic areas. Bilingual teaching means using two languages as a medium of teaching language, subject knowledge through learning to achieve the purpose of mastering a second language. Bilingual teaching is not a simple language and second language, but from the aspects such as listening, speaking, reading and writing to cultivate the students' second language comprehensive ability, thinking and problem solving skills in a second language, the essence is to prompt the development of students' language ability in teaching language. Bilingual 
teaching in ethnic regions, formulate bilingual teaching training target, according to the actual circumstance of the students' cognitive characteristics and writing textbooks. It should research feasible teaching goals and methods. Optimize the environment of classroom teaching, and improve the quality of teaching, perfect teaching evaluation and examination system. Stability of bilingual education teachers, in degree education, job title assess, and children education and family members of the work to give preferential policies. Give money compensation, to students of poor areas to ensure smooth completion of basic education. Through a series of effective measures promote national language protection.

(4) Carrying out national language research. National language is the treasure of Chinese culture, in-depth research on national language, plays an important role to the protection of national language. On the one hand, encourage social organizations and research institutions in government support, strengthening the research work of national languages, the national language using a database record and information technology, based on the existing knowledge and statistics, as well as collecting, editing, and analysis of the data, in-depth excavation of the national language contains cultural connotation; On the other hand, in the process of national language of the protection and inheritance, strengthen the research work, universities should give full play to the leading role, through the subject building and system optimization, constantly expand the breadth and depth of research. In addition, also want to carry out the economics of language studies, language has important economic value, national language is no exception. No matter from the perspective of language, language rights or language problems, national languages is very necessary for economic research. Economic development is not necessarily lead to the decline of national language and endangered.

(5) The construction of northeast China national language speech corpus. By scientific sampling and processing of large-scale corpus refers to the electronic library, the text is the basis of corpus linguistics research resources, the research methods of empirical main resources. Since the advent of computerized corpus, the fast development of corpus linguistics, the use of corpus for language contrast research, the study of language ontology has achieved fruitful results. Different from the traditional text corpus, the content of the speech corpus storage includes text, speech and acoustic parameters and so on. Speech corpus is based on facts, through natural means such as phonetic acquisition, storage, and labeling. Establish a national language speech corpus, national speech sounds can be permanent preservation, improve query, retrieval and statistical functions, provide service for national language protection, study and research. In the field of language technology processing, speech corpus is mainly used in speech recognition, speech synthesis, cross-language and multimodal human computer interaction technology, voice translation, etc.

\section{Conclusion}

Language and its derivatives as well as the communication tool and information carrier of modern society, and the modernization in various areas of basic resources, must from the strategic height to know state language as the strategic position and value of cultural resources. National language is gradually in the nation in the long-term historical development created, accumulated a national long-term model of thinking and behavior. National language is not only a kind of internal communication medium, but also an important symbol of mutual acceptance. Lost the national language, loses the important carrier of national culture, national culture inheritance is a great way. Research results, this paper solves the northeast national language resources protection of the key issues, to more integrated into the practical application of information technology, in order to adapt to the development of new media age.

\section{Acknowledgement}

This work is supported by Project on economic and social development in Liaoning (2017lslktyb-018): Research on Protection and Construction of National Language Resources in Northeast China. 


\section{References}

[1] L. Lin, "The evolution of Manchu and part of the northeast minority language relationship," Journal of Liaoning Teachers College (Social Sciences Edition), vol. 18, no. 1, pp. 15-16, 2016.

[2] Z. L. Ha, J. Q. Yang, "Experience and Enlightenment from the Protection of Overseas Ethnic Minorities' Languages," Guangxi Ethnic Studies, vol. 28, no. 2, pp. 189-193, 2012.

[3] H. M. Wang, "Study on the strategies of minority language protection and transmission in the new media era," Education for Chinese After-school, vol. 9, no. 1, pp. 1-4, 2015.

[4] F. Ji, "A study on the strategies of minority language protection and transmission in the new media era," Editorial Friend, vol. 34, no. 10, pp. 69-72, 2014.

[5] Baidu Knows, "Ideological role of television," https://zhidao.baidu.com/question/27746414.html, 2016-11-1.

[6] Baidu Knows, "Bilingual education," https://zhidao.baidu.com/question/12283781.html, 2016-11-1.

[7] Velislava Stoykova. Teaching Corpus Linguistics[J]. Procedia - Social and Behavioral Sciences. 2014, 143(8): 437-441.

[8] Y. Liu, "The Design of Speech Corpus of Chinese Endangered Minority Languages," Journal of The Central University For Nationalities, vol. 33, no. 4, pp. 133-136, 2006.

[9] H. Zhang, Y. H. Yang, "Abroad Sociolinguistic Perspectives for Protecting Endangered Minority Languages," Modern Management, vol. 33, no. 4, pp. 194-197, 2012.

[10] L. Li, "Protection status and countermeasure research on minority language: In the Naxi language as an example," Journal of Jiangsu Second Normal University, vol. 30, no. 7, pp. 42-45, 2014.

[11] F. L. Kong, W. X. Yin, "Connotation and Significance of Bilingual Ethnic Education in China," Journal of Northwest University for Nationalities (Philosophy and Social Science), vol. 38, no. 1, pp. 179-182, 2016.

[12] Blanka Frydrychova Klimova. Using Corpus Linguistics in the Development of Writing[J]. Procedia - Social and Behavioral Sciences. 2014, 141(1): 124-128. 